\title{
Основина Т.Ю. \\ Полифункциональность профессиональной деятельности бакалавров социальной работы по профилю «Управление и предпринимательство в социальной сфере» как признак транфессии
}

Нижнетагильский государственный сочиально-педагогический институт (филиал) ФГАОУ ВПО «Российский государственный профессионально-педагогический университет» (Россия, Нижний Тагил)

doi: 10.18411/trnio-10-2021-12

\section{Аннотация}

Представлены полифункциональный состав и ролевой спектр деятельности бакалавра социальной работы регламентированный образовательной программой по профилю «Управление и предпринимательство в социальной сфере» и ФГОС 39.03.02, как базовые признаки транфессии.

Ключевые слова: управление, социальная работа, транфессия, транспрофессионализм, полифункциональность, полифункциональная деятельность.

\section{Abstract}

The article presents the multifunctional composition and role spectrum of the Bachelor of social work activity regulated by the educational program on the profile "Management and entrepreneurship in the social sphere" and the Federal State Educational Standard 39.03.02, as the basic signs of a transfession.

Keywords: management, social work, transfession, transprofessionalism, polyfunctionality, polyfunctional activity.

Система социальной работы самым тесным образом переплетается с другими социальными системами: экономикой, политикой, правом, культурой, этикой, экологией, социально-бытовым обслуживанием и т.д. Понимание и видение связей системы социальной работы с другими системами дает возможность говорить о феномене транспрофессионализма, который проявляется в полипрофессионализме.

Социальная работа — это комплексный процесс, требующий от специалиста устойчивых знаний в области теории управления, экономики, психологии, социологии, педагогики, права. Данный вид трудовой деятельности, реализуется на совокупности профессиональных компетенций, принадлежащих к разным специализированным областям, следовательно, может быть отнесен к транфессии, профессиональной деятельности основанной на широком спектре специализированных видов операций. Теоретической основой трансфессии выступает ее полифункциональность, требующая сочетание знаний из наук: естественных, технических, социально-гуманитарных философских.

Транспрофессионализм предполагает приоритет основной профессиональной подготовки, но предполагает расширение спектра компетенций специалиста, за счет знаний и умений в области технологий, которые имеют отношение к другим видам профессиональной деятельности. Условием выхода специалиста на транспрофессиональный уровень может стать полифункциональность базовой профессии.

Специалисты транспрофессионального типа, способны работать в межпрофессиональной среде. Эффективность профессионального процесса во многом зависит от самого специалиста социальной работы, его умений, опыта, личностных особенностей и качеств.

Сам характер современной социальной работы требует от специалиста социальной работы квалифицированного решения широкого круга вопросов, напрямую связанных с социальными технологиями, многоуровневостью управленческих задач, с актуальной потребностью реализации предпринимательских технологий в этой профессиональной области. 
Поэтому выполнение бакалавром социальной работы полифункциональной социальной, социально-эконимической и управленческой деятельности - это базис для профессионального обучения бакалавров.

Определяя, специфику управления социальной работой, главенствующую позицию занимает его социальная направленность, в силу того, что управление направлено на социум, призвано решать его социальные задачи, в плоть до проблем отдельно взятого человека. Соответственно, управленческая деятельность в социальной работе имеет четко выраженную социальную направленность и правомочно может быть установлена как социальноуправленческая деятельность, сочетающая множество профессиональных функций.

Полифункциональная деятельность - это выполнение субъектом нескольких функций для решения различных задач.

Полифункциональность деятельности это всесторонний охват всего спектра конкретной деятельности или разнообразные роли, выполняемые определенным элементом социальной системы в ее организации и в осуществлении целей и интересов социальных групп.

Полифункциональность деятельности заключается в выполнении объектом нескольких функций, широко используется для решения практических задач в большинстве областей человеческой деятельности.

Специфика полифункциональности социально-управленческой деятельности в социальной работе определяется исходя из следующих аспектов:

1. организационно-структурный. Управление социальной работой организуется на различных уровнях.

2. управление как процесс, включающий следующий ряд элементов:

- целевая ориентация. Основа любого вида управления - информация, на базе которой определяются и закрепляются (в организационноадминистративных документах) цели, задачи;

— и расстановка кадров;

- соответствие целей, задач и решений ресурсам (информационным, материальным, трудовым, финансовым, временным);

- использование разнообразных форм и методов управления или средств, которые обеспечивают достижение результатов;

- использование обратной связи, а именно учет, контроль, проверка исполнения.

3. вид профессиональной деятельности, управленческий труд, включающий триаду: предмет труда (информация), средства труда (организационные и технические) и специалист, обладающий определенными знаниями, навыками и умениями.

Деятельность специалиста социальной работы является полисубъектной: во-первых, он выступает субъектом влияния во взаимодействии с клиентом, во-вторых, он субъект личностного и профессионального развития (саморазвития и самореализации), в-третьих, - субъект формирования и развития социальной службы как организации и, в-четвертых, - субъект взаимодействия с ближайшим окружением клиента, его семьей, родственниками. Множественная субъектность специалиста социальной работы в социально-управленческой деятельности так же определяет ее полифункциональность.

Полифункциональность состоит из общих и конкретных функций. Общими функциями, т.е. независимыми от уровня субъекта, его компетенции и т.д., считаются прогнозирование, планирование, организация, координация, стимулирование, учет и контроль. 
Конкретные функции - виды работы применительно к должности (обязанности и права), подразделению (функции подразделения) и предприятию, организации, учреждению (направления деятельности в социальной сфере).

Трансфессионализм демонстрирует готовность и способность специалиста осваивать и выполнять действия по функционально близким профессиям и выражается в полифункциональности, многозадачности, профессиональной мобильности.

Полифункциональность социально-управленческой деятельности специалиста социальной работы реализуется в функциях, которые он выполняет в процессе своей работы: информационноаналитическая, мотивационно-целевая, планово-прогностическая, организационно-исполнительская, контрольно-диагностическая, регулятивно-коррекционная.

Разнообразные функции специалиста находят отражение в разнообразии выполняемых ролей. Он является организатором, администратором, психологом, социальным психологом, информационным работником, юристом, экономистом, политиком, предпринимателем, педагогом, что то же доказывает полифункциональность деятельности бакалавра социальной работы. Его деятельность раскрывается через следующие функции:

- диагностическая - анализ специфики групп и сообществ, личности, степень и направленность воздействия на них макросреды и определяет «социальный диагноз»;

- прогностическая - прогноз событий, процессов, реализующихся в группе или сообществе для выбора модели социального поведения;

- правозащитная - применение нормативно-правовых актов регулирующих процессы в социальной сфере;

- организационная - активизация профессиональной деятельности в социальной сфере, привлечение к социальной работе общественности, направление деятельности специалистов на решение социальных проблем; предупредительно-профилактическая - разработка и реализация технологий (юридических, психологических, социально-медицинских, педагогических) предупреждения и нейтрализации негативных событий;

- социально-медицинская - формирует процесс профилактики заболеваний, пропагандирует здоровый образ жизни, содействует снижению негативного влияния стрессовых факторов социально-профессиональной деятельности;

- социально-педагогическая - формирует культурно-воспитательную среду, позволяющую реализовать потребности разных категорий населения в культурно-досуговой, спортивно-оздоровительной, художественной деятельности и привлекает к этой работе соответствующие организации;

- психологическая - консультационная помощь в решении межличностных проблем, в адаптации личности к социальной или профессиональной среде, в социальной реабилитации после изменений условий жизнедеятельности индивида;

- социально-бытовая - реализация всего спектра необходимой помощи и поддержки различным категориям населения, находящихся в трудной жизненной ситуации и не способных к самообслуживанию;

- коммуникативная - формирование двусторонних связей между специалистом и представителями социальной сферы, обеспечение информацией, передача опыта, побуждение к действию;

предпринимательская - обеспечивает систематическое получение прибыли от пользования собственностью, выполнения работ или оказания социальных услуг.

Согласно ФГОС 39.03.02 реализуя данные функции специалист социальной работы может выступать в роли: 
1) консультанта, передача информации, необходимой для принятия решения в той или иной проблемной ситуации;

2) организатора, активизация всех видов ресурсов для устранения трудной жизненной ситуации клиента;

3) социального адвоката, защита, посредничество, переговоры в интересах клиента в конфликтных ситуациях;

4) активатора социальных изменений повышающих уровень качества жизни населения в целом и отдельно взятого человека;

5) предпринимателя в сфере социального бизнеса.

Качество и эффективность управления и предпринимательства в социальной работе зависит от уровня компетентности специалиста социальной работы, понимая полифункциональность его деятельности.

Процесс подготовки бакалавров по социальной работе к полифункциональной деятельности требует теоретического анализа всего спектра функций, обеспечивающих эффективность управления и предпринимательства в социальной сфере, только тогда специалист будет готов к встрече с социально-профессиональными инновациями будущего, так как будет владеть востребованной обществом трансфессией.

$$
* * *
$$

1. Зеер, Э. Ф. Психолого-педагогическая платформа формирования транспрофессионализма педагога профессионального образования / Э. Ф. Зеер // Профессиональное образование. Столица. - 2017. - № 6. - С. 5-9.

2. Зеер Э. Ф. Методологические ориентиры развития транспрофессионализма педагогов профессионального образования / Э. Ф. Зеер, Э. Э. Сыманюк // Образование и наука. 2017. Т. 19, № 8. С. 9-28.

3. Федеральный государственный образовательный стандарт высшего образования. Бакалавриат. Направление подготовки. Социальная работа. [Электронный ресурс], режим доступа http://www.consultant.ru/document/cons_doc_LAW_194219/

\section{Основина Т.Ю. \\ Специфика использования технологии мастер-класса со студентами профиля «Управление и предпринимательство в социальной сфере» как методической формы реализации практических занятий по курсу «Маркетинг социальных услуг»}

Нижнетагильский государственный сочиально-педагогический институт (филиал) ФГАОУ ВПО «Российский государственный профессионально-педагогический университет»

doi: 10.18411/trnio-10-2021-13

(Россия, Нижний Тагил)

\section{Аннотация}

Проанализирована специфика и возможность использования технологии мастеркласса как методической формы реализации практических занятий по курсу «Маркетинг социальных услуг».

Ключевые слова: мастер-класс, технология мастер-класса, мастер, практикоориентированная подготовка студентов, маркетинг социальных услуг.

\section{Abstract}

The article analyzes the specification and the possibility of using the technology of the master class as a methodological form of implementation of practical classes in the course "Marketing of social services".

Keywords: master class, master class technology, master, practice-oriented training of students, marketing of social services.

В современной системе образования в области социальной работы ведущим является практико-ориентированное обучение, что позволяет спроектировать учебный процесс как 